\title{
Los insectos de Xochimilco alimento de alto contenido en proteínas
}

\author{
Virginia Melo Ruiz, Maritza García Núñez, María Luisa Machado Marquetti, Héctor Daniel Jiménez Aguirre \\ RESUMEN
}

Xochimilco es un centro importante en producción de nutrientes desde la época prehispánica hasta la actualidad, tanto para consumo local como de la metrópoli (Sahagun 1975). En esta región, la cultura indígena ha basado su alimentación, en la ingesta de maíz, chile, frijol, vegetales e insectos y bebidas como el pulque y agua de frutas; sin embargo, algunos recursos renovables del lugar no han sido debidamente estudiados. En Xochilmico se cuenta con más de veinte especies de insectos comestibles, de los cuales en esta investigación se presentan cinco de ellos, que corresponden a las estudiadas, y disponibles en diferentes épocas del año, de consumo y aceptación por diferentes grupos sociales. Gusanos de tepozán, gusanillos de nopal, capulmimichis, picudo de nopal y gusanos de maíz los cuales poseen un contenido de proteínas que va desde 45.25 a $60.75 \%$ y todos ellos con ocho aminoácidos esenciales. Estos organismos se consumen en estado larvario. Los insectos estudiados son ingeridos de forma alternativa ya que su disponibilidad es temporal; sin embargo, representan una fuente considerable de macronutrientes y en todos los casos están en un balance adecuado a los requerimientos para una buena nutrición.

Palabras claves: insectos comestibles, nutrición, ecología

\section{Xochimilco bugs food with high protein content}

\begin{abstract}
Xochimico, important center for production of nutrients from prehispanic times to present, for local and engulfed the metropolis (Sahagun 1975). In this region, the nutrition of the native culture has been based in corn, chili, beans, vegetables and insects, and beverages like pulque and fruit water; however some renewable resources, have not been properly studied. Xochimilco has twenty or more species of eatable insects, for the research are show five of them, it belongs to the study, and are available in different seasons, consumed and accepted by different social groups. Tepozan worms, nopal worms, capulmimichis, nopal picudo, and corn worms, these have a protein content from $45.25 \%$ to $60.75 \%$ and all of them with eight essential amino acids. These organisms are consumed in the larva stage. These insects are eaten as an alternative because its availability is temporary; nevertheless, these represent an important source of macro nutrients, and in all the cases have the right balance to have a good feeding.
\end{abstract}

Key words: eatable insects, nutrition, ecology.

Correspondencia: Virginia Melo Ruiz, Maritza García Núñez, María Luisa Machado Marquetti, Héctor Daniel Jiménez Aguirre. Universidad Autónoma Metropolitana Xochimilco. Calz. del Hueso 1100. Col. Villa Quietud 04960 México, D.F. E-mail: vmelo@correo.xoc.uam.mx,

$\mathrm{E}$ n un momento tan crítico como el que vivimos, se acentúa el esfuerzo en todos los niveles por solucionar de manera adecuada las diferentes crisis, como la contaminación ambiental, educación, sobrepoblación y la más dramática de todas, la alimentación. Los problemas para alcanzar y mantener la obtención suficiente de alimentos, de alto valor nutritivo para satisfacer las necesidades de una población en constante crecimiento, son tanto de naturaleza política como técnica; sin embargo, la administración adecuada de estos recursos necesita tomar en cuenta las realidades biológicas ya que mientras el hombre está cada día más hambriento y la demanda de alimentos continua incrementándose, es prioritaria la búsqueda de nuevas fuentes de nutrientes ricos en proteínas que mejoren sustancialmente la alimentación y salud. En consecuencia el proceso de desarrollo económico en dichas poblaciones es importante, para evitar la creación de procesos de cambio enmarcados en un clima de violencia surgidos de una población mal alimentada. 


\section{OBJETIVOS}

- Investigar hábitos alimenticios de habitantes de Xochimilco y su estado nutricional.

- Estudiar los insectos comestibles disponibles en la delegación de Xochimilco.

- Analizar el contenido de macronutrientes de los insectos de consumo por los habitantes de Xochimilco.

\section{MATERIAL Y MÉTODOS}

Se realizó una investigación longitudinal cuantitativa con un muestreo por conveniencia en función de la accesibilidad de insectos y alimentos silvestres no cultivados, ya que no se podía verificar su control y otros factores que influirían en la variación del muestreo, mismo que proporcionará a la investigación elementos necesarios para determinar el valor nutritivo de las diferentes variedades de insectos comestibles disponibles en la delegación Xochimilco, datos que serán aplicados en el mejoramiento de alimentación de los habitantes de la región.

El estudio se realizó en dos fases, una de campo para ubicar las diferentes áreas de trabajo y captura del material entomológico y otra de laboratorio en la que se identificó la taxonomía de las especies capturadas, mediante un análisis proximal de macronutrientes para determinar el valor nutritivo de los organismos en estudio.

En la etapa de trabajo de campo se incluyó visita periódica (cada semana durante tres meses) a una zona rural, suburbana y urbana de la delegación Xochimilco; previo establecimiento de las mismas, para investigar el consumo de alimentos naturales e industrializados para determinar la cantidad de nutrientes y calorías de los alimentos ingeridos por día, para relacionarlos con el grado de nutrición de los individuos tomando en cuenta la ocupación de los mismos y así considerar sus requerimientos, se entrevistaron un total de 150 familias, y una muestra de 50 familias por cada zona, para evaluar en forma cualitativa y cuantitativa los alimentos consumidos, durante una semana.

Al mismo tiempo se estudio la ecología de la zona para ubicar especies disponibles de insectos y hospederos; así como, condiciones bióticas y abióticas del entorno y para determinar la posible disponibilidad de cada especie a lo largo del año. Por otra parte, se investigó el estado de desarrollo de insectos considerados comestibles para no afectar los ciclos biológicos y no caer en la disminución drástica de alguna especie.

\section{RESULTADOS}

Los insectos estudiados fueron identificados según su taxonomía como se expone en la siguiente tabla.
Tabla 1. Determinación taxonómica de 5 especies de insectos comestibles de Xochimilco.

\begin{tabular}{c|c|c|c|c|c}
\hline Orden & Lepidoptera & Lepidoptera & Lepidoptera & Coleoptera & Lepidoptera \\
\hline Familia & Geometridae & Pyralidae & Pieridae & Curculionidae & Noctuidae \\
\hline Género & Synopsia & Laniffera & Catasticta & Metamasius & Heliothis \\
\hline Especie & Mexicanaria w. & Cyclades $d$. & Teutila D. & Spinolae V. & Zea b. \\
\hline $\begin{array}{l}\text { Nombre } \\
\text { común }\end{array}$ & $\begin{array}{c}\text { Gusano de } \\
\text { tepozán }\end{array}$ & $\begin{array}{c}\text { Gusanillo de } \\
\text { nopal }\end{array}$ & $\begin{array}{c}\text { Capulmimichis o } \\
\text { gusano de } \\
\text { capulin }\end{array}$ & Picudo de nopal & Guzano de maíz \\
\hline \multicolumn{7}{l}{ Fuente. Datos del estudio. }
\end{tabular}

Se encontró que la disponibilidad de los especimenes (tabla 2) no está presente en todo el año y al investigar su ecología se identificaron; las fechas en las que se les puede encontrar, así como el estadio morfológico en el que la población suele consumirlos.

Tabla 2. Disponibilidad de diferentes especies de insectos de Xochimilco en el año.

\begin{tabular}{ccc}
\hline Insecto & Fecha & $\begin{array}{c}\text { Estado de desarrollo } \\
\text { comestible }\end{array}$ \\
\hline Gusano de nopal & febrero a julio & Larva \\
Gusano de tepozán & julio a noviembre & Larva \\
Gusano de capulín & septiembre a febrero & Larva \\
Gusano de maíz & junio a diciembre & Larva \\
Picudo de nopal & enero a abril y junio a & Larva \\
\hline Fuente. Datos del estudio. & septiembre &
\end{tabular}

Al comparar el contenido nutricional de los insectos analizados (gráfica 1), se puede observar que la proteína se encuentra en cantidades que rodean el $50 \%$ del total analizado, en los cinco organismos estudiados, además presentan una diferencia poco significativa entre ellos. También se observa un bajo contenido de fibra indispensable para una buena digestión, así como de minerales. En el caso de los lípidos su presencia está entre el 19 y 31\% en los insectos estudiados lo cual es importante al no encontrarse en forma excesiva.

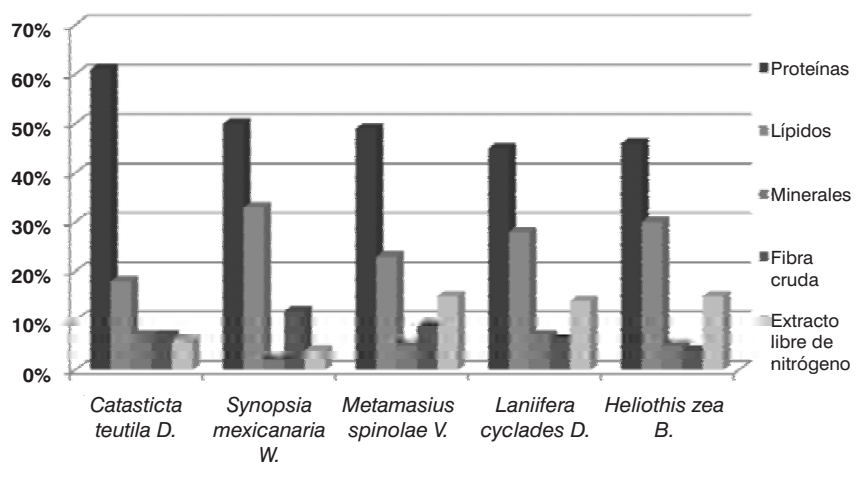

Fuente. Datos del estudio.

Gráfica 1. Valor nutritivo de algunas especies de insectos comestibles en Xochimilco g/100g base seca. 
En la tabla 3; se puede observar la comparación realizada de los aminoácidos que el humano necesita ingerir al día (PETRON FAO, 1973).

Tabla 3. Contenido de aminoácidos de algunas especies de insectos comestibles en Xochimilco.

\begin{tabular}{|c|c|c|c|c|c|c|}
\hline $\begin{array}{l}\text { Aminoacidos } \\
\text { esenciales }\end{array}$ & $\begin{array}{l}\text { Patron } \\
\text { FAO 1973 }\end{array}$ & $\begin{array}{l}\text { Laniifera } \\
\text { Cyclades } d .\end{array}$ & $\begin{array}{l}\text { Synopsia } \\
\text { Mexicanaria w. }\end{array}$ & $\begin{array}{l}\text { Catasticta } \\
\text { Teutila d. }\end{array}$ & $\begin{array}{c}\text { Heliothis } \\
\text { Zea } b .\end{array}$ & $\begin{array}{l}\text { Metamasius } \\
\text { Spinolae v. }\end{array}$ \\
\hline Isoleucina & 4.0 & 4.3 & 4.5 & 4.1 & 5.0 & 4.7 \\
\hline Leucina & 7.0 & 7.1 & 7.3 & 7.2 & 8.0 & 6.9 \\
\hline Lisina & 5.5 & 5.5 & 5.0 & 5.6 & 5.5 & 5.2 \\
\hline $\begin{array}{l}\text { Meionina+ } \\
\text { Cistina }\end{array}$ & 3.5 & 4.0 & 3.3 & 3.2 & 3.8 & 3.1 \\
\hline $\begin{array}{l}\text { Fenilalanina+TI } \\
\text { Rosina }\end{array}$ & 6.0 & 7.1 & 6.3 & 6.1 & 7.5 & 5.9 \\
\hline Treonina & 4.0 & 4.1 & 4.4 & 4.3 & 4.5 & 4.1 \\
\hline Triptofano & 1.0 & 0.5 & 0.7 & 0.9 & 0.4 & 1.1 \\
\hline Valina & 5.0 & 4.8 & 5.4 & 5.1 & 5.5 & 5.1 \\
\hline
\end{tabular}

Fuente. Datos del estudio.

Tabla 4. Ocupación de 50 jefes de familia en tres zonas de la delegación Xochimilco.

\begin{tabular}{lccc}
\hline Ocupación & Rural & Suburbana & Urbana \\
\hline Trabajo agrícola & 23 & 12 & - \\
Agrícola y obrero & 9 & 3 & - \\
Obrero de construcción & 6 & 5 & 6 \\
Agrícola y comerciante & 11 & 12 & 8 \\
Comerciante & & & \\
Chofer & 1 & 8 & 17 \\
Empleado & - & 4 & 5 \\
Profesionista & - & 3 & 6 \\
Policia & - & 2 & 7 \\
\hline Fuente. Datos del estudio. & - & 1 & 1 \\
\hline
\end{tabular}

Tabla 5. Consumo promedio de los principales alimentos naturales e industrializados, en 50 jefes de familia de tres zonas de la delegación Xochimilco, durante tres meses.

\begin{tabular}{|c|c|c|c|c|}
\hline Alimentos & $\begin{array}{c}\text { \# personas } \\
\text { rural }\end{array}$ & $\begin{array}{l}\text { \# personas } \\
\text { suburbana }\end{array}$ & $\begin{array}{c}\text { \# personas } \\
\text { urbana }\end{array}$ & $\begin{array}{c}\text { Contenido } \\
\text { proteico } \mathrm{g} / 100 \mathrm{~g} \\
\text { peso neto }\end{array}$ \\
\hline Maiz $^{1}$ & 50 & 50 & 50 & 5.0 \\
\hline Pan, galletas & 11 & 29 & 43 & 9.5 \\
\hline Pastas & 2 & 12 & 21 & 9.4 \\
\hline Arroz & 5 & 28 & 27 & 7.4 \\
\hline Frijol & 50 & 50 & 50 & 21.8 \\
\hline Leche $^{2}$ & 9 & 11 & 17 & 9.5 \\
\hline Huevo & 8 & 12 & 21 & 11.0 \\
\hline Carne $^{3}$ & 9 & 13 & 25 & 28.0 \\
\hline Insectos ${ }^{4}$ & 36 & 19 & 12 & 31.5 \\
\hline Chile & 41 & 39 & 40 & 2.3 \\
\hline Vegetales $^{5}$ & 32 & 36 & 46 & 2.0 \\
\hline Frutas $^{6}$ & 23 & 41 & 46 & 0.7 \\
\hline Azúcar & 31 & 39 & 41 & - \\
\hline Grasas & 18 & 37 & 43 & - \\
\hline
\end{tabular}

Fuente: datos del estudio. 1. Tortillas, atole, elotes. 2. Leche de vaca, industrializada con café, cuatro veces a la semana. 3. Pollo o carne de puerco una vez a la semana, 2 veces al mes. 4. Gusano de nopal, picudo de nopal, gusano de maíz, gusano de capulín. 5. Nopal, espinaca, zanahoria, papa quelites. 6. Naranja, platano, tuna y capulín.

\section{DISCUSIÓN}

Se analizó la cantidad en gramos de insectos que son necesarios para cubrir los requerimientos nutricionales de un individuo adulto sano las cuales son mayores que otras fuentes de proteínas tradicionales, su costo es inferior pues la obtención de insectos es sencilla en la mayoría de los casos. Los insectos estudiados contienen ocho aminoácidos esenciales y en todos los casos el triptófano es limitante, la fibra está presente en cantidades bajas y los lípidos en su mayoría son monoinsaturados y poliinsaturados. Los carbohidratos solubles son fuentes de energía; en algunos casos bajos, la diferencia en requerimientos se puede balancear con lípidos. Los escamoles para conservar su precio alto no son explotados en su totalidad, o se usan en autoconsumo para así disminuir su nivel de existencia en el mercado (Melo, V. 1992).

\section{CONCLUSIONES}

Los ingresos de los habitantes de la zona rural son bajos pues en su mayoría son campesinos y ellos están relacionados con los precios de garantía de los productos básicos, hay pocos obreros y comerciantes; sin embargo, todos presentan un alto grado de autoconsumo, al conocer más insectos que en otras zonas; esto se debe a hábitos de herencia de todas las especies menos gusanos de elote que en principio rechazaron y chapulín que desconocían su uso; no obstante, la inmigración de una familia de Oaxaca inicio a los habitantes del lugar, en el consumo de esta especie.

La zona suburbana tiene un mayor número de comerciantes; así sus ingresos son mayores y las posibilidades de adquisición de productos alimenticios son mejores aunque no se descarta el autoconsumo, aquí también hay ingesta de insectos. Por último, la zona urbana esta determinada por un mayor consumo de alimentos industrializados, el consumo de insectos se limita a chapulines y escamoles como platillo exótico.

A los individuos que se les invitó a participar en el análisis sensorial en donde se les dio a conocer que lo único que comerían serián insectos, siendo estos aceptados en forma satisfactoria aún cuando muchos de ellos nunca los habían consumido. Una gran cantidad de habitantes de Xochimilco se dedican al comercio, recolección y venta de insectos en los mercados de forma natural y procesados en restaurantes está será una fuente mayor de trabajo que puede coadyuvar a mejorar la alimentación y condiciones económicas de las familias de la Delegación Xochimilco

\section{BIBLIOGRAFÍA CONSULTADA}

1. AOAC. Official methods of analisis, Association of Official Analytical Chemists. Arlinton, W. S. Ed. Virginia, USA. 1990.

2. Cibrian D, Méndez JT, Campos R. Insectos forestales de México. 2000 .

3. FAO/WHO. Report: energy and protein requirements. Expert Comitee. 1973.

4. Greenfield H, Southgate DA T. Datos de composición de alimentos. FAO. Roma. 312. 2006.

5. Melo V. Diez especies de insectos comestibles en la Delegación 
Xochimilco de origen prehispánico. III Congreso Internacional de la ANQUE Vol. II. España. 1992.

6. Melo V. Insects indigenous food for Mexican people. 18th. International Congres of Nutrition. Durban South Africa. 2005.

7. Morón MA, Terrón RA, Entomología práctica. Instituto de Ecologia, México, D.F. 1968.
8. Osborne DR. Análisis de nutrientes de los alimentos. Ed. Acribia, España. 1985.

9. Sahagún FB. 1830. Historia general de las cosas de la Nueva España T. III Cap. V. del Libro II s/ed. México.

10. Speight MR, Hunter MD, Watt AD. Ecology of insects. Blackwell Science, Ltd. London. 1999. 